\title{
Value of clinical examination in the assessment of penetrating neck injuries: a retrospective study of diagnostic accuracy test
}

Andrés Isaza-Restrepo ${ }^{1,2^{*}}$ D, Julián Andrés Quintero-Contreras ${ }^{3}$, Jorge Escobar-DiazGranados ${ }^{1}$ and Ángela María Ruiz-Sternberg ${ }^{1}$

\begin{abstract}
Background: There are many high-volume trauma centers in limited resource environments where a thorough clinical examination of patients may contribute to a more economical, accurate, and widely applicable method of determining the proper management of patients with penetrating neck injuries. The purpose of this study was to validate thorough physical examination as a reliable diagnostic tool in these patients.

Methods: We performed an observational retrospective study of a diagnostic accuracy test where we compared clinical findings (symptoms and soft signs on admission of the patient) with the definitive findings according to the gold standard test for each particular situation (selective studies, clinical observation and surgical exploration). The study was conducted at Hospital Occidente Kennedy (HOK) between August 2009 and June 2010.

Results: The sample consisted of the clinical records of $207(n=207)$ patients who went to the emergency room for penetrating neck wounds at Hospital Occidente Kennedy (HOK). Of the total sample, $36.2 \%(n=75)$ of patients were considered "asymptomatic" as they didn't present with any soft signs of injury. Vascular soft signs were present in $57 \%(n=118)$ of the patients, soft signs of the airway and the upper gastrointestinal tract were present in $15.9 \%(n=33)$ and $21.3 \%(n=44)$ of the patients respectively. The sensitivity and negative predictive value (NPV) of any soft sign to determine injuries which require surgical repair was 97.4\% [CI] [86.5-99.5\%] and 98.7\% [Cl] [92.8-99.8\%] respectively, with a range of confidence [Cl] of 95\%.

Conclusions: Our study's main findings suggest that patients with neck injuries and no vascular, airway, or gastrointestinal soft sign can be safely managed with a conservative approach. It is important to emphasize the value of the clinical examination since there are many contexts in the modern world where a considerable amount of the population is afflicted by neck trauma and treated under conditions where technological resources are limited.
\end{abstract}

Keywords: Penetrating neck injuries, Vascular, Airway and gastrointestinal signs, Health resources

\footnotetext{
* Correspondence: andres.isaza@urosario.edu.co

${ }^{1}$ Escuela de Medicina y Ciencias de la Salud. Grupo de Investigación Clínica,

Universidad del Rosario, Carrera 24 No 63C-69 Barrio Siete de Agosto,

Bogotá, DC, Colombia

${ }^{2}$ Méderi Hospital Universitario Mayor, Bogotá, DC, Colombia

Full list of author information is available at the end of the article
}

(c) The Author(s). 2020 Open Access This article is distributed under the terms of the Creative Commons Attribution 4.0 International License (http://creativecommons.org/licenses/by/4.0/), which permits unrestricted use, distribution, and reproduction in any medium, provided you give appropriate credit to the original author(s) and the source, provide a link to the Creative Commons license, and indicate if changes were made. The Creative Commons Public Domain Dedication waiver (http://creativecommons.org/publicdomain/zero/1.0/) applies to the data made available in this article, unless otherwise stated. 


\section{Background}

The neck has a dense concentration of vital structures confined in a small space. Any intrusion may result in lifethreatening penetration of the trachea or larynx, the esophagus, major blood vessels, cervical nerve roots, cervical nerves or the spinal cord $[1,2]$. Penetrating neck injury (PNI) constitutes $5-10 \%$ of traumatic injuries in adults and has a mortality rate ranging from 10 to $15 \%$ [1, 2]. Different characteristics of neck trauma are usually related to the social and cultural conditions of the population. Penetrating neck injuries are more likely to occur in highly populated areas where there is more interpersonal violence and more gun and knife crime between young men [3]. Additionally, the rise of global terrorism and continuing wars in the Middle East has perpetuated head and neck injuries in the civilian population leading to elevated morbidity and mortality rates $[4,5]$.

Previously many centers advocated for mandatory surgical exploration irrespective of signs or symptoms. Such policies are associated with a high incidence of unnecessary operations, ranging from 30 to $89 \%$ [6]. Different studies suggest operative management is required more frequently with gunshot wounds than with stab wounds, even though the majority of PNIs are caused by stab wounds, with only a minority by gunshot injuries $[3,7]$. In recent years, selective management of penetrating neck trauma based on clinical examination has been recommended. This has seemed to reduce, on the one hand, the percentage of negative examinations, and on the other hand, a significant number of costly diagnostic tests, many of which are not available in some institutions, which also generate unnecessary prolongation of hospital stays [6].

However, management of PNI remains controversial. Over the last decade, most trauma centers have now adopted the approach of selective management based on a combination of clinical examination and the use of diagnostic tools [8]. In particular, developments in computed tomography angiography (CTA) have provided a fast, accurate, non-invasive method for evaluating patients with penetrating neck injuries [8].

Although, in settings where resources are limited and this technology is not yet available, other types of studies (angiography, bronchoscopy and/or esophagoscopy) still hold high sensitivity for detecting injuries. These exams are also invasive for the patient and carry a small but serious risk of complications [9]. The high incidence of PNIs due to interpersonal violence within cities and due to the continuation of wars in the Middle East raises questions as to whether patients should be managed by using CTA as the gold standard diagnostic approach or if efforts must be focused on the rational use of technology. This being even more so when the value of the clinical examination plays a very important role defining the management of the patient $[8,9]$.
The current trend in literature is to argue the selective use of different diagnostic methods depending on the clinical findings upon admission [10]. High-volume trauma centers are more frequently turning to the selective non-operative management (SNOM) approach when treating PNIs. This type of management is based on clinical examination or other additional examinations. Together, they have shown to be reliable indicators of clinically significant injury, with a sensitivity of $93-95 \%$ and a negative predictive value of $97 \%[10,11]$.

Bearing in mind the changes in the management of PNIs, our study aims to provide information on the value of the clinical examination in the assessment of penetrating neck wounds, in scenarios where there is a high volume of trauma and there are limited resources for decision making. To this end, a diagnostic accuracy test study was designed to evaluate the diagnostic value of clinical findings in neck trauma (to identify the presence of lesions that warranted further study or surgical intervention). Our research shows the experiences within a trauma referral center with limited resources in Bogotá, Colombia. In this study, we aimed to evaluate the diagnostic accuracy of clinical findings in patients with penetrating neck injuries compared with definitive findings found trough gold standard test, clinical follow-up and/or surgical exploration and to determine its diagnostic potential in patients attended in limited resource settings.

\section{Methods}

We performed an observational retrospective study to compare the diagnostic accuracy of clinical findings (symptoms and soft signs on admission of the patient) with the definitive findings according to the gold standard test for each particular situation in patients with PNI admitted to the Hospital Occidente Kennedy's (HOK) emergency department from August 2009 until and including June 2010. Kennedy is a middle to low income borough in Bogota. It is the second largest borough in the city, with approximately one million inhabitants, from which its majority belongs to an age group between 25 to 29 years old [12]. Between 2009 and 2010 this locality accounted for 12\% of the felonies in the city and had the highest number of cases of theft, traffic accidents and homicides [13]. When information was gathered, approximately 2000 trauma patients were admitted in HOK facilities annually, with $8 \%$ of the cases being associated with penetrating neck injuries. We determined the diagnostic accuracy of clinical findings following the Standards for Reporting Diagnostic accuracy studies (STARD) 2015 guidelines [14].

Patients admitted to the HOK emergency department with neck wounds that extended deep to the platysma were considered for inclusion. The selected group was between 14 and 65 years of age. They underwent an interview and a complete physical examination, and a 
form was filled out by the surgeon on duty, where he/ she focused on soft signs and symptoms that would lead the physician to suspect lesions in the upper gastrointestinal tract, airway lesions in the neck and/or vascular lesions. Patients with penetrating neck trauma who were initially resuscitated according to the Advanced Trauma Life Support guidelines and remained hemodynamically unstable were excluded from the study [15]. Patients were also excluded and taken immediately to the operating room if they presented "hard signs" including signs of vascular injury (active severe bleeding, expanding hematoma, absence of peripheral pulse, arterial bruit, thrill, and unexplained hypotension) and aerodigestive injury (respiratory distress, massive subcutaneous emphysema, air bubbling through the neck wound and massive hemoptysis) [15]. Additionally, patients were excluded if they were dead on arrival (DOA), those with insufficient data in the clinical record or without clinical follow-up, and patients with cranioencephalic and/or spinal cord trauma of whom, due to their clinical condition, necessary information couldn't be collected.

After a comprehensive clinical evaluation, patients included in the research were categorized into two groups according to their signs and symptoms. The first group consisted of patients with "soft signs" including signs of vascular injury (minimal bleeding, mild to moderate bruising, hypotension that responds to resuscitation, and murmur fluids) and aerodigestive injury (hoarseness, stridor, minimal hemoptysis, subcutaneous emphysema, odynophagia, dysphagia and hematemesis) [15]. The second group was comprised of patients who did not present any hard or soft signs upon clinical examination, and so were considered "asymptomatic" (however still presenting with PNI) and would undergo close observation and series of physical tests for $24 \mathrm{~h}$.

To determine whether patients required any surgical repair, we used three gold standard tests. The surgeon on duty decided between three different types of patient management according to the initial clinical findings: 1 . Request selective studies: Fibrobronchoscopy (airway), arteriography and/or duplex studies (vascular), upper digestive endoscopy (upper gastrointestinal tract). 2. Surgical exploration: intraoperative findings. 3. Clinical observation: patients that the surgeon on duty left in clinical observation for $24 \mathrm{~h}$ in the emergency service and hereafter were discharged. Subsequently, a follow-up was carried out by external consultation or a telephone call 30 days after the trauma where a questionnaire was carried out to determine if the patient presented late signs or symptoms that required complementary studies, or if they were asymptomatic, at which point the patients were considered to be fully recovered.

Clinical findings were compared using two-by-two contingency tables, the accuracy of the soft signs of vascular, airway and digestive injury was estimated comparing patients who required surgery with patients who didn't (according to the gold standard in each patient). Additionally, 95\% confidence intervals (CI) were calculated. Data was collected in a pre-established format and analyzed with the statistical packages STATA version 9 and SPSS version 17. A descriptive analysis of the variables was carried out, and sensitivity, specificity, positive and negative predictive values of clinical examination were calculated.

\section{Results}

The sample consisted of the clinical records of 207 ( $n=$ 207) patients who were admitted for penetrating neck

Table 1 Demographics, clinical data and soft signs for patients with PNI.

\begin{tabular}{|c|c|}
\hline \multicolumn{2}{|c|}{ Demographics, clinical data and soft signs for patients with PNI. } \\
\hline & $\mathbf{n = 2 0 7}$ \\
\hline Age (years), mean -SD & 29.22 - (SD:11.92) \\
\hline Male (\%) & $182(87.9 \%)$ \\
\hline $\begin{array}{c}\text { Time elapsed between the time of injury and their } \\
\text { admission to the hospital (median - IQR) }\end{array}$ & 60 minutes - (IQR: 30-180 \\
minutes)
\end{tabular}




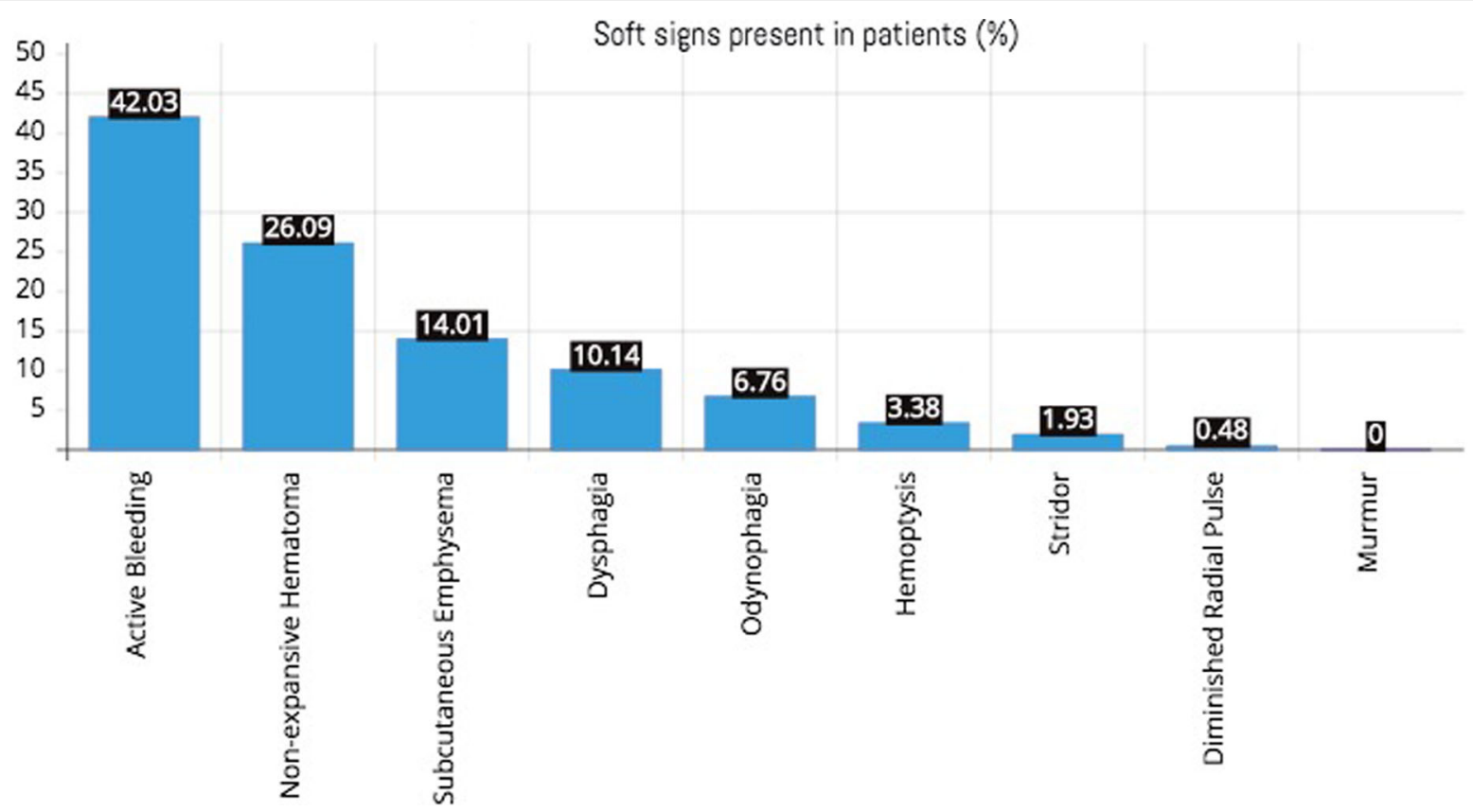

Fig. 1 Soft signs present in patients (\%)

wounds at HOK between August 2009 and June 2010 and met the inclusion criteria. The majority were male, the mean age was 29.22 years (SD:11.92). The most frequent neck injuries were caused by stab wounds and mainly affected the zone II of the neck (Table 1).

Vascular soft signs were present in 118 (57\%) patients, $87(42 \%)$ patients presented minimal bleeding, followed by $54(26 \%)$ who presented non-expansive hematomas. The soft signs of the airway and the upper gastrointestinal tract were present in $33(15.9 \%)$ and $44(21.3 \%)$ patients, respectively. With regards to the airway and in the upper gastrointestinal tract, the most frequent sign was subcutaneous emphysema present in 29 (14.1\%) patients. Hemoptysis occurred in only 7 patients and stridor in 4 patients. Dysphagia occurred in 21 (10.1\%) patients and odynophagia in 14 (6.8\%) (Fig. 1).

Regarding the diagnostic and/or therapeutic approach of the 207 patients, 95 (45.9\%) underwent the set of selective studies. Upper digestive tract endoscopy was performed in 95 patients and did not show evidence of any lesion. Only one patient had an abnormal fibrobronchoscopy, underwent surgical exploration and required surgical repair of the trachea (although this patient presented with a vascular soft sign). Carotid duplex was performed in 80 patients and only one patient needed surgical repair (internal carotid stent). Additionally, of the 22 arteriographic studies performed, only one patient showed evidence of lesions that required surgical repair (internal

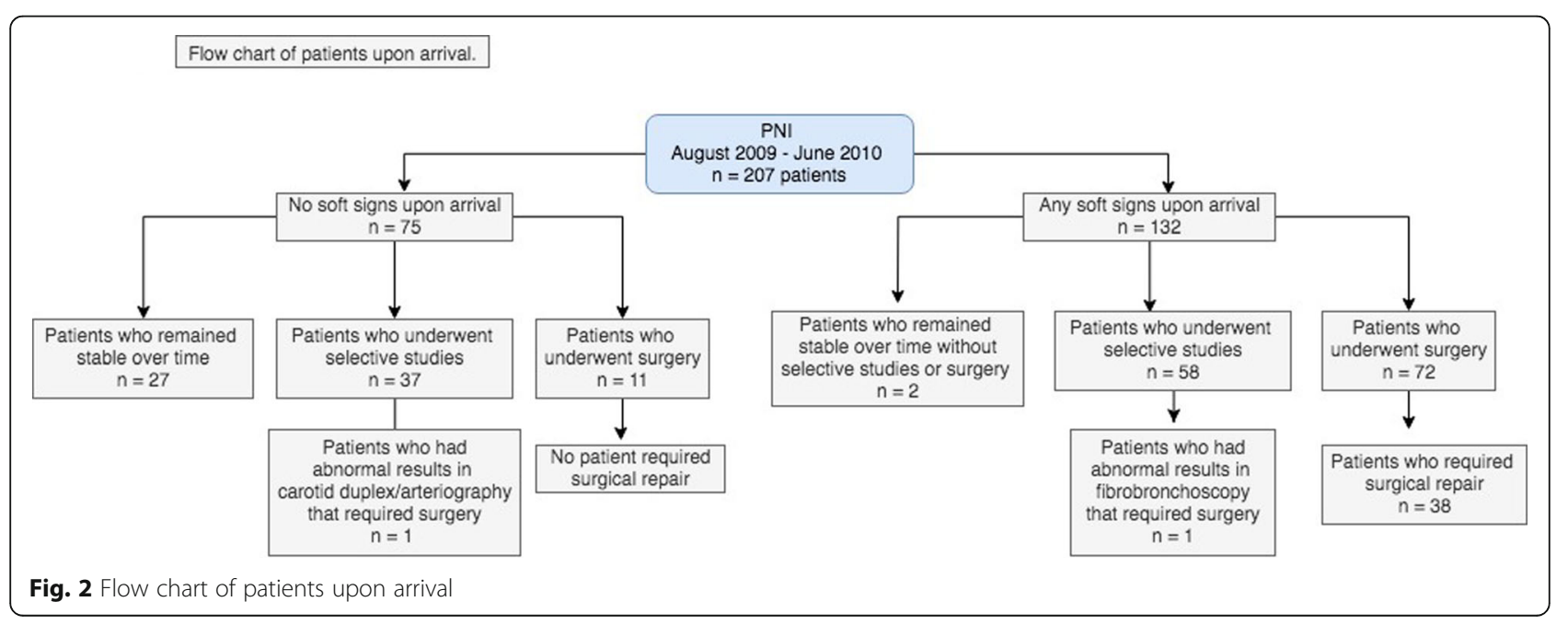


Table 2 Diagnostic accuracy of soft signs to determine patients who requiere surgical repair.

\begin{tabular}{|c|c|c|c|c|c|c|}
\hline \multicolumn{7}{|c|}{ Diagnostic accuracy of soft signs to determine patients who requiere surgical repair } \\
\hline & Vascular soft sign & $\mathrm{Cl} 95 \%$ & Airway soft sign & $\mathrm{Cl} 95 \%$ & Any soft sign & $\mathrm{Cl} 95 \%$ \\
\hline Sensitivity & $95.65 \%$ & $79.0 \%-99.2 \%$ & $93.75 \%$ & $71.7 \%-98.9 \%$ & $97.37 \%$ & $86.5 \%-99.5 \%$ \\
\hline Specificity & $47.83 \%$ & $40.7 \%-55.0 \%$ & $90.58 \%$ & $85.6 \%-94.0 \%$ & $43.79 \%$ & $36.5 \%-51.3 \%$ \\
\hline $\begin{array}{c}\text { Positive Predictive } \\
\text { Value }\end{array}$ & $18.64 \%$ & $12.6 \%-26.6 \%$ & $45.45 \%$ & $29.8 \%-62.0 \%$ & $28.03 \%$ & $21.1 \%-36.2 \%$ \\
\hline $\begin{array}{c}\text { Negative Predictive } \\
\text { Value }\end{array}$ & $98.88 \%$ & $93.9-99.8 \%$ & $99.43 \%$ & $96.8-99.9 \%$ & $98.67 \%$ & $92.8-99.8 \%$ \\
\hline
\end{tabular}

carotid stent), while another patient had a vertebral artery thrombosis which was managed during the procedure.

Furthermore, from the $83(40.1 \%)$ patients who underwent surgical exploration, $60(72.3 \%)$ patients showed no lesions of vital structures. Some type of vascular lesion was identified in $23(27.7 \%)$ patients (total or partial section of the anterior or external jugular veins; in three cases evidence was found of injuries to the internal carotid and the internal jugular). Airway injury was identified in $16(20 \%)$ patients; all cases were characterized by perforations of the trachea. No injury of the upper gastrointestinal tract was identified in this series of patients. From the 75 (36.2\%) patients categorized in the "asymptomatic" group (as they didn't present any soft sign of injury), 37 (49.3\%) had complementary studies where only one needed surgical repair (internal carotid stent). Additionally, 11 (14.6\%) patients were taken to surgery and none required any repair. Of the $207 \mathrm{pa}$ tients, only $30(14.5 \%)$ patients had clinical follow-up, and none required further assessment.

Of the 207 patients, only 38 (18.4\%) had injuries that required surgical repair: $23(11.1 \%)$ of the patients presented vascular lesions and 16 (7.7\%) airway lesions. Only one patient needed repair of a vascular and airway injury (external jugular and trachea). A flow chart is shown to represent the management of the 207 patients upon arrival (Fig. 2).

\section{Analytical statistics}

The validation analysis showed in Table 2 demonstrates that the clinical finding of any soft sign has a sensitivity of $97.37 \%$, with a specificity $43.79 \%$, a positive predictive value (PPV) of $28.03 \%$ and a negative predictive value
(NPV) of $98.67 \%$ to determine which patients required surgical repair. Two-by-two contingency Tables 3, 4 and 5 represent clinical findings on vascular, airway and any soft sings from which the results in Table 2 come.

Clinical findings of vascular and airway soft signs demonstrated high diagnostic value to identify injuries that require surgical repair. Diagnostic accuracy was calculated with a range of confidence of $95 \%$ [CI].

\section{Discussion}

Our study's main findings suggest that in settings with limited resources, patients with PNI and no vascular, airway or gastrointestinal soft sign can be safely managed with a conservative approach. These hold high negative predictive values in the absence of soft sings (NPV: 9399\%). Our findings also demonstrate that adequate identification of soft signs represents a reasonable screening tool for patients with PNIs, as it shows high sensitivity (97.4\%) [CI] [86.5-99.5\%] in determining patients who require surgical repair. Many high-volume trauma centers are using the Selective Non-operative Management Approach (SNOM) [7]. These works by determining the soft signs of vascular injury, airway injury and upper gastrointestinal tract lesion. SNOM help suspect vital structure lesions and to identify the need to carry out complementary studies [7]. Similar to our results, the study of Inaba et al. with 453 patients at two Level 1 trauma centers demonstrate that using physical examination to triage patients into those with hard signs, soft signs, and no signs of vascular and aerodigestive tract injuries was highly effective at minimizing the need for invasive imaging and the rate of negative surgical exploration [16]. Different studies validated the practice

Table 3 Vascular soft signs $2 \times 2$ contingency table.

\begin{tabular}{|c|c|c|c|}
\hline \multicolumn{4}{|c|}{ Vascular soft signs $2 \times 2$ contingency table } \\
\hline Vascular soft sign & Disease & No disease & Total \\
\hline Positive & 22 & 96 & 118 \\
\hline Negative & 1 & 88 & 89 \\
\hline Total & 23 & 184 & 207 \\
\hline
\end{tabular}


Table 4 Airway soft signs $2 \times 2$ contingency table.

\begin{tabular}{|c|c|c|c|}
\hline \multicolumn{4}{|c|}{ Airway soft signs $2 \times 2$ contingency table } \\
\hline Airway soft sign & Disease & No disease & Total \\
\hline Positive & 15 & 18 & 33 \\
\hline Negative & 1 & 173 & 174 \\
\hline Total & 16 & 191 & 207 \\
\hline
\end{tabular}

of SNOM as a safe an appropriate management strategy $[7,17]$.

Identification of vascular soft signs evidenced high sensitivity (95.6\%) [CI] [79-99.2\%] and NPV (98.9\%) [CI] [93.9-99.8\%] in order to determine patients who require surgical repair. The possibility of requiring surgical repair if one does not present any vascular soft sign is low. While some authors advocate mandatory vascular imaging following PNIs according to mechanism or zone, many studies have demonstrated the reliability of physical examination alone to exclude clinically relevant vascular injuries $[11,18]$. The no zone approach has become more relevant as identification of soft signs hold higher value to identify lesions that require repair, regardless of the zone of the neck injured [17]. A prospective observational study with 203 patients showed a negative predictive value (NPV) and specificity of 88.695.5\% and 90.7\% respectively, for all signs and symptoms mandating angiography [18]. Additionally, in a study conducted with 216 patients in Indiana the sensitivity and negative predictive value of physical examination for detecting vascular injuries requiring operative management were both $100 \%$ [11]. Moreover, the research of Menawat et al. conducted with 110 patients evidenced that 42 patients were determined to have no vascular injury based on lack of any physical findings [19]. According to our findings and evidence shown in literature it is safe to say that routine angiography may be unnecessary for patients with penetrating neck injuries and negative physical examination.

Taking into account soft signs of airway injury, our study showed a sensitivity of 93.8\% [CI] [71.7-98.9\%], a specificity of $90.6 \%$ [CI] [85.6-94\%], and a NPV of $99.4 \%$ [CI] [96.8-99-9\%] to diagnose airway injuries that required surgical repair. Patients presenting airway soft signs may be evaluated with bronchoscopy, esophagogram and esophagoscopy [11]. Nevertheless, new technologies such as CTA have demonstrated to hold high diagnostic accuracy when compared to the vascular and airway diagnostic gold standards. Different studies showed nearly 100\% sensitivity and specificity of CTA in detecting clinically significant vascular or aerodigestive injuries [17, 20-22].

As shown, any vascular or airway soft sign identified in patients should impact the management received. Different diagnostic studies (Arteriography, duplex of four vessels of the neck, bronchoscopy, esophagogram, esophagoscopy and more recently CTA) have shown high sensitivity and negative predictive values to determine injuries in patients with PNI [11, 21]. Although, we should bear in mind the significant resource implications associated with unnecessary utilization of diagnostic tools [16]. In a resource-limited environment, unnecessary procedures may be interpreted as the loss of opportunity in the care of many patients, which is why the confirmation of the safety and accuracy of physical examination in patients with PNI represents a valuable strategy towards a simpler, more economic, accurate, and widely applicable method of determining the proper management of these patients [23].

A consensus regarding the management of penetrating neck injuries has been sought around the world. It is clear that immediate neck exploration is warranted in unstable patients with "hard signs" of neck injury after optimal airway has been obtained [15]. In accordance to international literature, our study showed higher incidence of stab wounds than gunshot wounds as a result of interpersonal violence within city limits $[3,7,17,19,23]$. Nevertheless, higher incidence of gunshot wounds is evidenced in scenarios of war and armed conflict. Additionally, according to literature there's a higher prevalence of PNIs in men, and the most affected zone of the neck is usually zone II $[17-19,23]$. However, the type of management of the PNI

Table 5 Any soft signs $2 \times 2$ contingency table.

\begin{tabular}{|c|c|c|c|}
\hline \multicolumn{4}{|c|}{ Any soft signs $2 \times 2$ contingency table } \\
\hline Any soft sign & Disease & No disease & Total \\
\hline Positive & 37 & 95 & 132 \\
\hline Negative & 1 & 74 & 75 \\
\hline Total & 38 & 169 & 207 \\
\hline
\end{tabular}


shouldn't be determined by the mechanisms of assault or neck zone affected but by the signs and symptoms presented by the patient $[3,4,11,18]$.

There are some limitations to this study that need to be emphasized. Primarily, this was an observational retrospective study. If we wish for there to be a future paradigm shift towards a SNOM approach in scenarios of low resources, a prospective study would be more appropriate. Also, a bigger sample size could help corroborate our results. Additionally, the hospital where the study was conducted did not have available CTA imaging. As different studies showed a nearly $100 \%$ accuracy in detecting vascular and aerodigestive injuries, it would have been important to count on this diagnostic tool as a gold standard.

\section{Conclusions}

It is important to emphasize the value of clinical examination considering the many contexts in which the population is subjected to neck trauma and technological resources are limited. The loss of resources in unnecessary procedures, may be interpreted as the loss of opportunity of caring for many other patients in a resource-limited environment. The results of the present study indicates that physical examination is a reliable, simpler, economical, accurate, and widely applicable diagnostic tool. Furthermore, it can be specifically implemented and used systematically to diagnose the patient's signs and/or symptoms related to lesions of the digestive tract, vascular system, airway, and nervous system in contexts where more sophisticated technologies are not yet available.

\section{Abbreviations}

CTA: Computed Tomography Angiography; HOK: Hospital Occidente Kennedy; IQR: Interquartile Range; Cl: Confidence Interval; NPV: Negative Predictive Value; PNI: Penetrating Neck Injury; PPV: Positive Predictive Value; SD: Standard Deviation; SNOM: Selective Non-Operative Management

\section{Acknowledgements}

To all the participants of the study and to Hospital Occidente Kennedy.

\section{Authors' contributions}

AIR, JQ, AMRS conceived and designed the study, developed the theory, draft the manuscript and designed the Tables. JQ, AMRS and JED preformed the analytic calculations, contributed to the interpretation of the results and were in charge of overall direction and planning. AIR, JED, and AMRS helped in interpreting the results and worked on the manuscript. All authors discussed the results and contributed to the final version of the manuscript.

\section{Funding}

The authors declare that they have not received any kind of funding for the realization of this paper.

\section{Availability of data and materials}

The datasets used and/or analyzed during the current study are available from the corresponding author on reasonable request.

\section{Ethics approval and consent to participate}

This work did not involve direct interventions on the patients since the data was taken from the clinical records and the defined behaviors for the diagnosis and treatment were those that the surgeons of the service decided according to the criteria of their current practice. The conducts used to carry out arteriographies, endoscopies, fibrobronchoscopies, or explorations and / or surgical treatments are those that are usually taken in the emergency service for the management of penetrating injuries in the neck by the different surgeons of the service in Hospital Occidente Kennedy. There was no direct intervention on patients as part of the present investigation. The protocol of treatment of patients in HOK to perform any invasive examination or surgical procedure, includes that all patients must demonstrate their compliance with said behavior by signing a preestablished Informed Consent form for each service. The data was collected under the numbers of their clinical histories and the presentation of the results kept the anonymity of the patients and did not allow them to be identified in any way. The research project was submitted and approved by the Clinical Research Ethics Committee of the Universidad del Rosario. The planning and conduct of the project was carefully developed following the ethical guidelines contemplated in the Declaration of Helsinki and Resolution 8430 of 1993 of the Ministry of Health, and in accordance with this resolution was considered a risk-free study.

\section{Consent for publication}

Not applicable.

\section{Competing interests}

The authors declare that they have no competing interests.

\section{Author details}

${ }^{1}$ Escuela de Medicina y Ciencias de la Salud. Grupo de Investigación Clínica, Universidad del Rosario, Carrera 24 No 63C-69 Barrio Siete de Agosto, Bogotá, DC, Colombia. ${ }^{2}$ Méderi Hospital Universitario Mayor, Bogotá, DC, Colombia. ${ }^{3}$ Hospital Emiro Quintero Cañizares, Ocaña, Colombia.

Received: 23 July 2019 Accepted: 14 February 2020

Published online: 09 March 2020

\section{References}

1. Bell RB, Osborn T, Dierks EJ, Potter BE, Long WB. Basic and patient-oriented research: Management of Penetrating Neck Injuries: A New Paradigm for Civilian Trauma. J Oral Maxillofac Surg. 2007;65:691-705. https://doi.org/10.1016/j.joms.2006.04.044.

2. Demetriades D, Theodorou D, Cornwall E, Berne TV, Asensio J, Beizberg H, et al. Evaluation of penetrating injuries of the neck: Prospective study of 223 patients. World J Surg. 1997;21(1):41-8. https://doi.org/10.1007/ s002689900191.

3. Harris R, Olding C, Lacey C, Bentley R, Schulte KM, Lewis D, et al. Changing incidence and management of penetrating neck injuries in the South East London trauma centre. Ann R Coll Surg Engl. 2012;94(4):240.

4. Kocamer Şimşek B, Dağlı G, Dokur M, Uysal E, Çalıker N, Gökçe ON, et al. Characteristics of the injuries of syrian refugees sustained during the civil war. Ulus Travma Acil Cerrahi Derg. 2017;23(3):199-206. https://doi.org/10. 5505/tites.2016.95525.

5. Celikel A, Demirkiran DS, Zeren C, Arslan MM, Karaarslan B. A series of civilian fatalities during the war in Syria. Ulus Travma Acil Cerrahi Derg. 2014;20(5):338-42

6. Schwartz S, Shires T, Spencer F. Principios de Cirugía. Traumatismos, vol. 1:. México: Interamericana; 1991. p. 187-245.

7. Madsen AS, Laing GL, Bruce JL, Oosthuizen GV, Clarke DL. An audit of penetrating neck injuries in a South African trauma service. Injury. 2016;47: 64-9. https://doi.org/10.1016/j.injury.2015.07.032.

8. Siau RTK, Moore A, Ahmed T, Lee MSW, Tostevin P. Management of penetrating neck injuries at a London trauma centre. Eur Arch Otorhinolaryngol. 2013;270(7):2123-8. https://doi.org/10.1007/s00405-0122324-9.

9. Nowicki JL, Stew B, Ooi E. Penetrating neck injuries: a guide to evaluation and management. Ann R Coll Surg Engl. 2018;100(1):6-11. https://doi.org/10.1308/rcsann.2017.0191.

10. Van Waes OJ, Cheriex KCAL, van Riet PA, Vermeulen J, Navsaria PH, Nicol AJ. Management of penetrating neck injuries. Br J Surg. 2012;99:149-54. https://doi.org/10.1002/bjs.7733.

11. Azuaje RE, Jacogson LE, Glover J, et al. Reliability of physical examination as a predictor of vascular injury after penetrating neck trauma. Am Surg. 2003; 69(9):804-7.

12. Secretaría Distrital de Planeación (District Planning Secretariat). Visor de proyecciones de población SDP (SDP population projection viewer), Bogotá 
2019. http://www.sdp.gov.co/gestion-estudios-estrategicos/estudios-macro/ proyecciones-de-poblacion. Accessed 25 Jan 2020.

13. Cámara de comercio (Chamber of Commerce). Observatorio de seguridad en Bogotá: Balance del año 2009 (Security Observatory in Bogotá: Balance of the year 2009). Bogotá. 2010;38:1-74.

14. Bossuyt PM, Reitsma JB, Bruns DE, Gatsonis CA, Glasziou PP, Irwig L, et al. STARD 2015: an updated list of essential items for reporting diagnostic accuracy studies. BMJ (Clinical Research Ed). 2015;351:h5527-h.

15. Brasel KJ. Advanced trauma life support (ATLS ${ }^{\oplus}$ ): The ninth edition. J Trauma Acute Care Surg. 2013;74(5):1363-6.

16. Inaba K, Branco BC, Tung L, Reddy S, Demetriades D, Menaker J, et al. Evaluation of multidetector computed tomography for penetrating neck injury: A prospective multicenter study. J Trauma Acute Care Surg. 2012; 72(3):576-84. https://doi.org/10.1097/TA.0b013e31824badf7.

17. Prichayudh S, Choadrachata-anun J, Sriussadaporn S, Pak-art R, Sriussadaporn S, Kritayakirana K, et al. Selective management of penetrating neck injuries using "no zone" approach. Injury. 2015;46:1720-5.

18. Thoma M, Navsaria PH, Edu S, Nicol AJ. Analysis of 203 patients with penetrating neck injuries. World J Surg. 2008;32(12):2716-23. https://doi.org/10.1007/s00268-008-9766-7.

19. Menawat SS, Dennis JW, Laneve LM, Frykberg ER. Are arteriograms necessary in penetrating zone II neck injuries? J Vasc Surg. 1992;16(3): 397-401.

20. Munera F, Soto JA, Palacio D, Velez SM, Medina E. Diagnosis of arterial injuries caused by penetrating trauma to the neck: comparison of helical CT angiography and conventional angiography. Radiology. 2000;216:356-62.

21. Gonzalez RP, Turk B, Falimirski M, Holevar MR. Penetrating zone II neck injury: Does dynamic computed tomographic scan contribute to the diagnostic sensitivity of physical examination for surgically significant injury? A prospective blinded study. J Trauma. 2003;54(1):61-5. https://doi.org/10.1097/01.TA.0000046310.28475.8D.

22. Gracias VH, Reilly PM, Philpott J, Lee SY, Singer M, Schwab CW, et al. Computed tomography in the evaluation of penetrating neck trauma: A preliminary study. Arch Surg. 2001;136(11):1231-5.

23. Sekharan J, Dennis JW, Veldenz HC, Miranda F, Frykberg ER. Continued experience with physical examination alone for evaluation and management of penetrating zone 2 neck injuries: Results of 145 cases. $J$ Vasc Surg. 2000;32(3):483-9. https://doi.org/10.1067/mva.2000.109333.

\section{Publisher's Note}

Springer Nature remains neutral with regard to jurisdictional claims in published maps and institutional affiliations.

Ready to submit your research? Choose BMC and benefit from:

- fast, convenient online submission

- thorough peer review by experienced researchers in your field

- rapid publication on acceptance

- support for research data, including large and complex data types

- gold Open Access which fosters wider collaboration and increased citations

- maximum visibility for your research: over $100 \mathrm{M}$ website views per year

At $\mathrm{BMC}$, research is always in progress.

Learn more biomedcentral.com/submissions 